\title{
Are look-alikes confusing? The application of the DRM paradigm to test consumer confusion in counterfeit cases
}

\author{
Andrzej Falkowski • Justyna Olszewska • \\ Joanna Ulatowska
}

Published online: 13 February 2014

(C) The Author(s) 2014. This article is published with open access at Springerlink.com

\begin{abstract}
The Deese-Roediger-McDermott (DRM) paradigm was used to investigate consumer confusion between original and look-alike brands. The results showed that look-alike brands were falsely recognized at a higher rate than original brands and that modality (audio, visual, and audiovisual) had no effect on false recognition rates. The results suggest that the DRM paradigm provides a useful tool for analyzing consumer confusion, brand substitution, and trademark infringement.
\end{abstract}

Keywords DRM paradigm $\cdot$ Look-alike products · Original products $\cdot$ Consumer confusion $\cdot$ Memory distortions

\section{Introduction}

Marketing analysis shows that only about $3 \%$ of products in the marketplace do not need packaging (Sudol et al. 2000). The packaging is not only for protection but also attracts consumer's attention and makes products more distinctive than others.

\footnotetext{
A. Falkowski

University of Social Sciences and Humanities, ul. Chodakowska 19/31, 03-815 Warsaw, Poland

e-mail: andrzej.falkowski@swps.edu.pl

J. Olszewska

Academy of Management, ul. Sienkiewicza 9, 90-113 Lodz, Poland e-mail: justynao@umich.edu

J. Olszewska

Department of Psychology, University of Michigan, 1012 East Hall, 530 Church Street, Ann Arbor, MI 48109-1043, USA

J. Ulatowska $(\bowtie)$

Institute of Applied Psychology, Academy of Special Education, ul. Szczesliwicka 40 Bud. C, pok. 3621, 02-353 Warsaw, Poland e-mail: julatowska@aps.edu.pl
} 
However, not every company creates their products to be distinguishable from others. Rather, companies consciously try to imitate market leaders using similar colors, shapes, style of lettering, or design of logo to mislead the consumer that such a product has the same quality as the original brand (AIM 2004; for a review see Zaichowsky 2006). Products that significantly resemble the overall appearance of well-known brands by combining the distinctive visual features that are inherent to the original product with the slightly differentiated features are called "look-alikes" (AIM 2004; Balabanis and Craven 1997). The use of look-alikes raises objections from companies that own the original products and who had invested money to create distinguishable packaging that lets them achieve a leading market position as well as from consumers who may be misled and unwillingly buy the wrong product. The last two decades have given rise to many lawsuits initiated by the manufacturers of branded goods who claim that the look-alikes confuse customers and, in consequence, make them purchase the wrong products (Balabanis and Craven 1997). Are customers indeed confused by lookalike products?

Most studies on customer confusion related to look-alike products do not focus on experimental testing of memory distortions, but are based on consumers' opinions (ProMarka 2007), product similarity analysis (Kapferer 1995; Loken et al. 1986; Walsh et al. 2007, 2010), or situational factors of consumer confusion (Foxman et al. 1992). Balabanis and Craven (1997), for example, tested 50 shoppers when they were finishing their shopping and no consumer had falsely bought a look-alike product instead of an original.

However, another survey conducted by the Which? Group (2013) found that one fifth of the British participants reported having bought the wrong product because they were misled by the similarity of the packaging to that of the other product. Moreover, $30 \%$ of the consumers felt misled and $38 \%$ were annoyed by the fact of buying the wrong product. A survey conducted in Poland for the ProMarka-Association of Branded Goods Manufacturers (ProMarka 2007) found that $12 \%$ of the clients were not aware that look-alike products exist and $32 \%$ declared that they were not able to distinguish between original and look-alike products. Similar confusion among sport fans was also revealed for event sponsors - the participants had difficulties with correct discrimination between actual and foil sponsors of their teams and based their responses on the plausibility of a brand as a potential sponsor (Johar et al. 2006).

Studies show that look-alike products may disturb the perception of original brands due to weakening of the symbolism of those brands to specific social groups (Loken and Amaral 2013). Moreover, Johnson et al. (2013) conducted a research study commissioned by the British Intellectual Property Office that revealed that some consumers believe that products that look similar have similar product characteristics and similar origin. However, this effect was larger if the consumers have not used products within a particular product category. Although high numbers of consumers tested reported that the accidental purchase of look-alikes disadvantaged them, a substantial number of participants reported that such a purchase had some positive aspects.

In the present study, it was investigated whether brands from the same categories of products may elicit false memory and lead to recognizing of look-alike products as original ones that are usually the market leaders. It was hypothesized that one of the possible mechanisms responsible for consumer confusion might be spreading activation that occurs at encoding (Collins and Loftus 1975) and consequently, leads to 
associative memory distortion. Related concepts are linked in such a way that accessing one concept (e.g., door) sends activation across these linked pathways to related concepts (e.g., window). The spread of activation through the associative network primes related concepts and makes them more easily accessible. This activation process is automatic and not amenable to conscious control.

In a previous study, Nedungadi (1990) showed that conceptual priming of brands increased memory-based choice probability that may result from spreading activation (Collins and Loftus 1975). However, that experiment was limited to the products' names and not to the products' images. In the present study, the brands that had lookalike competitors regarding package similarities were chosen. It was aimed to test how the names and the images of the products activate memory traces. The experiment reported here was motivated by a desire to know whether category activation evoked by either a look-alike or the original product affects people's choices in the same way. If differences are obtained, it would suggest that processes responsible for memory distortions happen not only at encoding but also at retrieval.

Moreover, this situation may relate to both product images (pictorial presentation) and product names (auditory presentation). With regard to product images, people are exposed to memory errors that stem from the visual similarity of products. This similarity concerns perceptual features of product packaging, such as shapes or colors. The more similar two products are from the same category, the more likely potential customers will be confused. In this situation, it is clear how memory is sensitive to distortions. Memory distortions may also concern brand names (auditory presentation). Usually, a brand name is strongly related to its image (e.g., packaging). Therefore, it is possible that the product name depicts specific characteristics (e.g., logo, colors, or shapes) that can easily be brought to mind after hearing it. For example, on hearing the popular brand name McDonalds, most people create a mental image of the yellow "M" letter. If a look-alike's image was evoked following auditory name presentation, but only differed slightly from the prototype (the original), there is a chance of false recognition because the latter image is activated. This assumption is consistent with Paivio's $(1971,1986)$ dual coding theory, which states that people have the ability to code a concrete stimulus in two different ways (pictorial+verbal).

If these associative memory distortions occur at the time of product encoding, it is thus possible that testing with the Deese-Roediger-McDermott (DRM) paradigm (Deese 1959; Roediger and McDermott 1995) will detect them. In the standard version of the DRM paradigm, subjects are presented with lists containing associated words (e.g., bed, awake, night, etc.), all of which are related to one nonpresented critical lure (e.g., sleep). Next, they receive instructions either to recall or to recognize words from the lists. Participants were found to falsely recall the nonpresented critical word approximately $40 \%$ of the time, and the probability of recognizing critical lures as having been seen before was similar to the probability of recognizing studied words (Roediger and McDermott 1995).

Although the DRM procedure is widely used in memory studies, there are very few experiments that have applied this paradigm in the marketing context. Sherman and Moran (2010) applied the DRM paradigm to show how false memories were created for brand names. They presented the participants with brand names (e.g., Morrisons, Sainsbury's, and Waitrose) either in brand appropriate fonts or in a plain font. Memory distortions occurred both for recall and recognition of nonpresented but the most 
popular brands (e.g., TESCO). Moreover, the brand-specific fonts at study had no effect on recall, but increased overall recognition.

Associative memory distortions were also revealed by Wagner and Kronlund (2005, as cited in Mantonakis et al. 2008), who showed higher susceptibility to falsely recognize major brands than minor brands or their associates. In addition, exposition to direct competitors of major brand or their associates led to false reports of having seen the former (Kronlund and Yoon 2007). Similar semantic interference was also observed in terms of conceptual priming and showed that exposure to prototypical brands increased false recognition for competing brands in the same category (Mantonakis and Yoon 2009).

Although the DRM procedure was used to test memory distortions for both pictorial and verbal material (Israel and Schacter 1997), it should be stressed that in the experiments described above, only false memory for brand names was tested. In the present study, the DRM procedure was adopted to test asymmetry in the recognition of original and look-alike products presented both auditorially and pictorially. It was attempted to demonstrate both the potential and limitations of the application of this paradigm in marketing practice and to test whether this kind of memory distortion might be influenced by presentation modality during encoding and retrieval.

Previous studies applying the DRM paradigm showed that differences in false memory rate depend on either encoding or test conditions (Gallo et al. 2001; Israel and Schacter 1997; Smith and Hunt 1998). For example, Smith and Hunt (1998) showed that, in general, visual presentation of words, when compared with auditory presentation, reduces the rate of false memory because studying pictures results in more perceptually distinct memories than studying words. A decrease in false alarms was also observed by Israel and Schacter (1997). They presented subjects with lists that contained words (word-only condition) or words with black and white drawings (picture and word condition). The rate of false recognition was lower in the second group. In both studies, the authors argued that the distinctiveness heuristic is responsible for the results. Thus, the more distinct information is provided at the time of encoding, the more easily subjects should be able to reject a lure (i.e., a look-alike). It is then possible that encoding and retrieval of stimuli, for example, a product shown in a double modality (pictorial+auditory simultaneously), may improve the memory for encoded items and reduce memory errors. A memory trace for encoded items should be more vivid and, at retrieval, the distinctiveness heuristic may be used. Moreover, subjects should be more accurate when using both auditory and visual modalities because information is processed in two separate streams that differ in how information is represented and stored in memory (Penney 1989; see also Broadbent 1956; Hede 1980; Treisman and Davies 1973).

To sum up, the main objective of the current study was to test the particular kinds of memory associative errors that occur for brands, both in relation to their images (pictorial presentation) and names (auditory presentation) and that are caused by dishonest marketing competition. It is predicted that the image and/or the name of look-alike products (exemplars) will elicit false memory of original products (prototypes) in the procedure similar to the DRM paradigm. Based on previous studies on the DRM paradigm and distinctiveness heuristics (Israel and Schacter 1997), it is also predicted that presentation of products both pictorially and auditorially will reduce the false memory effect and improve recognition of the presented products. Although it is well established that both pictorial and verbal presentations are superior to only 
verbal presentation in the DRM paradigm, this procedure was not applied hitherto to test the consumers' confusion for brand names and packages.

\section{Methods}

\subsection{Experimental design}

To test the differences in recognition of original and lookalike products a $2 \times 3$ mixed design was used. The participants were assigned to one of the three groups differing in terms of modality of presentation (pictorial vs. auditory vs. double; a between-subjects factor). The within-subjects factor was a type of recognition test type, where the presence of the original product or look-alike product was manipulated.

\subsection{Participants}

A total of 135 participants were tested. All of the participants were undergraduate students $(19-29$ years old, $M=20.3$; standard deviation $(S D)=1.46)$. There were $79 \%$ women and $21 \%$ men.

\subsection{Stimuli}

Four categories of products were chosen for the study: energy drinks, stain removers, frozen vegetables, and universal food seasonings. In all categories, a pair of products had been the subject of litigation concerning visual similarities in packaging in recent years. Each of these products (original and look-alike) was used as a critical lure in one of the conditions of the main study. The foil products that were used in the encoding and recognition phase of the main experiment were chosen during the normative study.

In the normative study, 30 undergraduate students, who did not take part in the main experiment, were presented with lists of brands from the four categories (17 in each category) and were asked to choose the brands they knew (had heard of). The normative study also showed that the original products were always one of the three best known brands in each category. Look-alikes were always less recognizable, except the universal food seasonings, where look-alike products were almost as well known as the original (Table 1).

As a result of the normative study, overall 32 well-known brands (with the exception of look-alike products that were mostly poorly recognized) were chosen to create the test lists for the main study. The original and the look-alike products were counterbalanced across participants; thus, for half of the participants, two original

Table 1 Percentage familiarity of the originals and look-alikes in four categories

in parentheses

\begin{tabular}{lll}
\hline Category & Original & Look-alike \\
\hline Energy drinks & $0.93(2)$ & $0.10(14)$ \\
Stain removers & $0.87(1)$ & $0.33(8)$ \\
Frozen vegetables & $0.93(3)$ & $0.27(9)$ \\
Universal food seasonings & $0.97(2)$ & $0.93(4)$ \\
\hline
\end{tabular}


(e.g., energy drink and stain remover) and two look-alike brands (e.g., frozen vegetables and universal seasoning) were presented at encoding. In the first condition when the original brands appeared at encoding, then at test, the look-alike brands were presented. In the second condition when the look-alikes were at encoding, then at test, the participants recognized the original brands. For the other half of participants, these products also appeared, but in inverted configuration. This procedure ensured that all the participants encountered the original and the look-alike, but in different contexts (at encoding and at retrieval).

\subsection{Procedure and design}

Study phase The subjects were tested in small groups. They were told that the experiment was designed to test their memory and that they would be presented with commonly known products from four categories. The presentation consisted of 20 products blocked into four categories. In each category, a look-alike or an original product appeared along with four foil products (see Fig. 1). The subjects were divided into three different groups: pictorial, auditory, and both pictorial and auditory. In the pictorial condition, stimuli appeared on a screen as photographs of packages. Pictures appeared one at the time for $4 \mathrm{~s}$. Each picture was centered and of the same height. Between each picture, a blank screen appeared for $1 \mathrm{~s}$. In the auditory condition, the subjects heard the names of brands read by a female voice. In the double modality condition, they saw both the brand packages and heard the names. After studying the lists, the subjects were asked to solve a math problem. The time for the task was $2 \mathrm{~min}$. Subsequently, a 1-h break was taken.

Recognition test After the break, the participants were asked whether they recognized the products that were presented earlier. The test consisted of 20 items. Three types of probes were used for each category: a lure (a look-alike product if an original appeared during encoding, or an original product if a look-alike appeared during encoding), two old foil products, and two new foil products. The items were again presented pictorially, aurally, and in double modality. The products appeared randomly, one at a time and had consecutive numbers. The subjects were asked to write down the numbers of products that they recognized from the encoding phase.

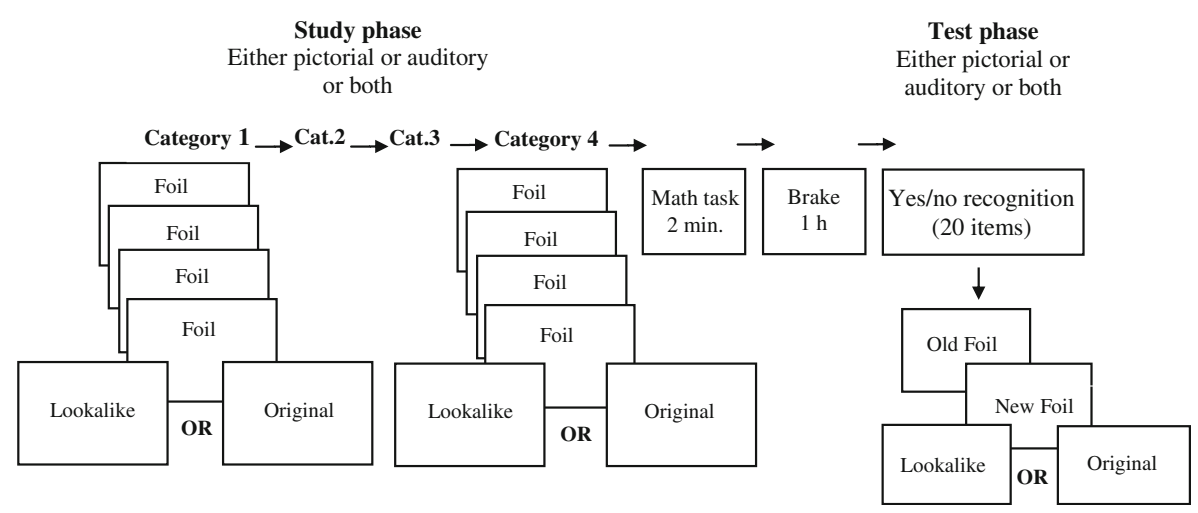

Fig. 1 Design of the study 
To sum up, the between-subjects manipulation of the study modality (visual, auditory, or mixed) was combined with the within-subjects manipulation of product type that had two levels: a look-alike and an original (one half of the participants from each modality received two look-alike products from two categories and two original products from two other categories in the encoding phase, whereas the other half received the inverse). Overall, six counterbalanced groups were tested.

\section{Results}

A series of analyses of variance was conducted to test the differences in false and correct recognition of both, the critical items (look-alikes and original products) and foil items depending on modality of presentation.

First, an analysis of variance (ANOVA) was conducted utilizing a 2 (recognition test: original product at test/look-alike product at test) $\times 3$ (modality: pictorial/auditory/ double) mixed design. The modality was a between-subjects factor, and the type of recognition test was a within-subjects factor. The analysis revealed a main effect for the recognition test $\left(F(1,132)=31.68, p<.001, \eta^{2}=.19\right)$. As displayed in Fig. 2 , the participants were more prone to falsely recognize an original product than a lookalike one. This clearly showed asymmetry in recognition. Neither the modality main effect $(F(2,132)=0.4$, not significant $($ n.s. $))$ nor the modality and false recognition interaction effect $(F(2,132)=1, n . s$. $)$ was significant, which is not surprising given that in all modality conditions, the scores for false recognition of originals were higher than the scores for the look-alikes.

Analysis of variances were also computed for the proportion of correct "yes" responses as well as for the proportion of false alarms toward the foil products. A significant effect of modality type was revealed for the proportion of hits

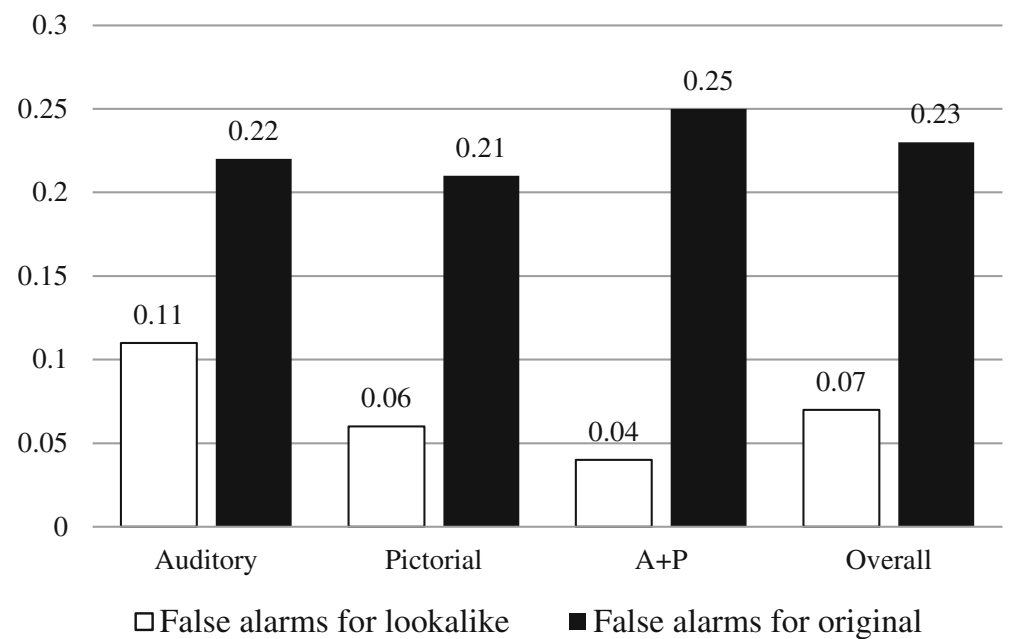

Fig. 2 Asymmetry in false recognition of look-alike and original products as a function of encoding/ recognition modality 
$\left(F(2,132)=13.25, p<.001, \eta^{2}=.17\right)$. The highest proportion of hits was obtained in the double modality condition $(M=0.94 ; S D=0.09)$ and was significantly higher than those in both the pictorial $(M=0.86 ; S D=0.13)$ and the auditory $(M=0.81$; $S D=0.14)$ conditions. Duncan post hoc tests showed significant differences between all groups $(p<.05)$.

A significant modality effect was also revealed for the false alarms toward foils $\left(F(2,132)=17.80, p<.001, \eta^{2}=.21\right)$. Post hoc tests showed that the false recognition rate was significantly lower in the double modality condition $(M=0.02 ; S D=0.04)$ than in either the pictorial $(M=0.13 ; S D=0.11$; all $p \mathrm{~s}<0.001)$ or auditory $(M=0.09$; $S D=0.11)$ conditions. The pictorial and auditory conditions did not differ significantly from each other.

\section{Discussion}

\subsection{Theoretical implications}

In the present study, the occurrence of false memory effects for brands was investigated within the procedure similar to the DRM paradigm and demonstrated two phenomena: first, the asymmetry in recognizing brands was obtained, i.e., look-alike products were falsely recognized at a higher rate than the original products. Second, the modality did not affect false memory, showing similar pattern in three different modalities of encoding and retrieving brand information: pictorial, auditory, and double modality.

This experiment adopted the DRM paradigm for generating reliable false memory errors for brands; the use of five associated brand names and their packaging showed practical applications for the DRM paradigm that has been of interest to investigators since the beginning of the 1990s. This practical experiment distinguishes this work from traditional investigations in the DRM paradigm, in which semantically related words were falsely recalled and recognized at the same rate as that for presented items.

The results obtained support the activation-monitoring account (Roediger et al. 2001), according to which the critical lure that, in this case, was the original brand was activated through spreading activation processes as participants encoded related items - look-alike products. The activation converging on the original brand increased its familiarity, leading to memory errors at the time of test, when subjects mistakenly attributed the item's familiarity to a study event. The original product's high activation made monitoring more difficult and encouraged subjects to respond old (seen before) to these items. However, a visible asymmetry was obtained that showed a higher rate of false recognition for original products following look-alike presentation than for lookalike ones after the original products were encoded. This asymmetry is consistent with the results obtained by Wagner and Kronlund (2005, as cited in Mantonakis et al. 2008), who found that subjects more often falsely recognized major brands than minor brands or associates, and also those of Kronlund and Yoon's (2007) study, in which participants reported having seen a major brand when in fact they had been exposed to direct competitors of that brand or their associates.

What mechanisms might underlie the asymmetry that is reported? Tversky's (1977) theory of similarity provides an account of these data. His theory violates the 
commonly held rule of symmetry that states that A is similar to B as much as B is similar to A (when A is similar to B, then B is similar to A) and shows a tendency to select the more salient stimulus (or the prototype) as a referent and the less salient stimulus (or the variant) as a subject: We say that an ellipse is like a circle, rather than a circle is like an ellipse. In this experiment, a look-alike product (exemplar of the category) activated a corresponding category and the most representative product (prototype) that depicts Tversky's theory and can serve as a practical example. This theory, together with the DRM procedure that elicited this asymmetry, may be used to prove the rights of original products in the competitive market.

The second hypothesis, concerning encoding and retrieval modality, was only partially supported. First, consistent with the expectations, hits were visibly higher when double modality was used at encoding and retrieval. This is in accordance with Paivio's $(1971,1975,1978)$ dual coding theory and the multicomponent system of working memory developed by Baddeley and colleagues (Baddeley and Hitch 1974; Baddeley and Logie 1999), as well as with Penney's (1989) separate-stream hypothesis. According to Baddeley's theory, the visual-spatial sketchpad and the phonological loop systems of working memory are developed into two separate but interconnected channels (visual/pictorial and auditory/verbal). When items appear as pictures together with spoken words (dual modality presentation), they are processed in two channels, i.e., hypothesized to be better for learning than single modality formats because they take advantage of the two parallel channels. These processes that engage two channels strengthen the representation held in the memory. Separate-streams hypothesis (Penney 1989) also readily explains why bimodal encoding resulted in higher accuracy. The processing of auditorially and visually presented items is carried out separately in shortterm memory, and processing mechanisms are specific to either the auditory or the visual stream. These two streams represent information in different ways that make the representation richer and more detailed; thus, at the time of retrieval, subjects are more likely to use the distinctiveness heuristic.

\subsection{Managerial implications}

In the present study the DRM paradigm was applied to test false memories for brands. The results let conclude two robust phenomena that can be used by marketers.

First, this procedure is congruent with the line extension strategy. Well-known brands usually extend their line offering more diverse products (e.g., traditional shampoo vs. colored hair shampoo vs. curly hair shampoo, etc.). When a new product is similar to the original one, it is perceived to be strongly related to the original product. Thus, there is no need to use additional and sophisticated marketing strategies that integrate the newly launched product with its prototype, because the new product automatically activates the beliefs about the original one and, subsequently, in the consumer's mind, it becomes strongly associated with its prototype. This may be easily detected by the DRM procedure.

Second, the asymmetry clearly shows that look-alike products may contribute to dishonest marketing competition. As original brands do not activate look-alikes, lookalikes can easily activate their prototypes. Consequently, memory errors for original brands arise after the corresponding category is activated. This finding may be used to reinforce the ownership of the legal rights of the original brand, and the DRM 
procedure may successfully be applied to verify the extent to which look-alike products may replace the original products in the mind of a consumer.

Marketers around the world from Apple (technology products) to Coach (purses, wallets, etc.) find themselves in the competitive position of having to respond to companies that are manufacturing products that are "knock-offs" (cheaply made lookalike products with very subtle differences, but a strong similarity to the authentic brand), stealing market share from their company and deceiving the consumers. To effectively respond to this kind of market thievery, it may take a legal case in the courts to argue that the fake products are in fact perceived to be the real thing when actually they are not. The research reported in this study could be used to support such court cases.

Acknowledgments This research was supported by the National Science Centre Grant DEC-2011/01/D/ HS6/05482.

Open Access This article is distributed under the terms of the Creative Commons Attribution License which permits any use, distribution, and reproduction in any medium, provided the original author(s) and the source are credited.

\section{References}

AIM - European Brands Association. (2004). Appearances can be deceptive. Dealing with unfair look-alikes. Brussels: AIM.

Baddeley, A. D., \& Hitch, G. J. (1974). Working memory. In G. H. Bower (Ed.), The psychology of learning and motivation: Advances in research and theory (Vol. 8, pp. 47-89). New York: Academic.

Baddeley, A. D., \& Logie, R. H. (1999). Working memory: The multiple-component model. In A. Miyake \& P. Shah (Eds.), Models of working memory (pp. 28-61). Cambridge: Cambridge University Press.

Balabanis, G., \& Craven, S. (1997). Consumer confusion from own brand lookalikes: an exploratory investigation. Journal of Marketing Management, 13, 299-313.

Broadbent, D. E. (1956). Successive responses to simultaneous stimuli. Quarterly Journal of Experimental Psychology, 8, 145-152.

Collins, A. M., \& Loftus, E. F. (1975). A spreading-activation theory of semantic processing. Psychological Review, 82, 407-428.

Deese, J. (1959). On the prediction of occurrence of particular verbal intrusions in immediate recall. Journal of Experimental Psychology, 58, 17-22.

Foxman, E. R., Berger, P. W., \& Cote, J. A. (1992). Consumer brand confusion: a conceptual framework. Psychology and Marketing, 9, 123-140.

Gallo, D. A., McDermott, K. B., Percer, J. M., \& Roediger, H. L. (2001). Modality effects in false recall and false recognition. Journal of Experimental Psychology: Learning, Memory, and Cognition, 27, 339-353.

Hede, A. J. (1980). Dichotic and bisensory grouping effects. Quarterly Journal of Experimental Psychology, 32, 295-306.

Israel, L., \& Schacter, D. L. (1997). Pictorial encoding reduces false recognition of semantic associates. Psychonomic Bulletin and Review, 4, 577-581.

Johar, G. V., Pham, M. P., \& Wakefield, K. L. (2006). How event sponsors are really identified: a (baseball) field analysis. Journal of Advertising Research, 46, 183-198.

Johnson, P., Gibson, J., \& Freeman, J. (2013). The impact of lookalikes. Similar packaging and fast-moving consumer goods. Newport: The Intellectual Property Office. Retrieved June 20, 2013, from: http:/www. ipo.gov.uk/ipresearch-lookalikes-main.pdf.

Kapferer, J.-N. (1995). Brand confusion: empirical study of a legal concept. Psychology and Marketing, 12, 551-568.

Kronlund, A., \& Yoon, C. (2007). Consumer consideration sets: altering memory, brand evaluations, and choice. Advances in Consumer Research, 34, 407-408.

Loken, B., \& Amaral, N. (2013). Brand dilution: the impact of the user of counterfeits on original brand perception. Advances in Consumer Research, 37, 859-860. 
Loken, B., Ross, I., \& Hinkle, R. L. (1986). Consumer confusion of origin and brand similarity perceptions. Journal of Public Policy and Marketing, 5, 195-211.

Mantonakis, A., \& Yoon, C. (2009). The effects of conceptual priming on stimulus-based choice. Advances in Consumer Research, 8, 50-57.

Mantonakis, A., Whittlesea, B. W. A., \& Yoon, C. (2008). Consumer memory, fluency and familiarity. In C. P. Haugtvedt, P. M. Herr, \& F. R. Kardes (Eds.), The handbook of consumer psychology (pp. 77-102). New York: Lawrence Erlbaum Associates.

Nedungadi, P. (1990). Recall and consumer consideration sets: influencing choice without altering brand preference. Journal of Consumer Research, 17, 263-276.

Paivio, A. (1971). Imagery and verbal processes. New York: Holt, Rinehart, and Winston.

Paivio, A. (1975). Perceptual comparisons through the mind's eye. Memory and Cognition, 3, 635-647.

Paivio, A. (1978). Comparisons of mental clocks. Journal of Experimental Psychology: Human Perception and Performance, 4, 61-71.

Paivio, A. (1986). Mental representations: A dual coding approach. Oxford: Oxford University Press.

Penney, C. J. (1989). Modality effect and the structure of short-term verbal memory. Memory \& Cognition, 17, $398-422$.

ProMarka: The Polish Association of Branded Goods Manufacturers. (2007). Counterfeit and lookalike products - social awareness. Retrieved December 5, 2011, from http:/www.aim.be/Documents/Misc/ poland_aware.pdf.

Roediger, H. L., III, \& McDermott, K. B. (1995). Creating false memories: remembering words not presented in lists. Journal of Experimental Psychology: Learning, Memory, and Cognition, 21, 803-814.

Roediger, H. L., III, Balota, D. A., \& Watson, J. M. (2001). Spreading activation and arousal of false memories. In H. L. Roediger \& J. S. Nairne (Eds.), The nature of remembering: Essays in honor of Robert G. Crowder (pp. 95-115). Washington, DC: American Psychological Association.

Sherman, S. M., \& Moran, E. J. (2010). Creating false memories for brand names. Applied Cognitive Psychology, 25, 336-340.

Smith, R. E., \& Hunt, R. R. (1998). Presentation modality affects false memory. Psychonomic Bulletin and Review, 5, 710-715.

Sudol, S., Szymczak, M., \& Haffer, M. (2000). Marketingowe testowanie produktów. Warszawa: PWE.

The Which? Group (2013). Own-label 'copycat' products: can you spot the difference? Retrieved June 20, 2013, from: http://www.which.co.uk/news/2013/04/own-label-copycat-products-can-you-spot-thedifference-316370/.

Treisman, A. M., \& Davies, A. (1973). Divided attention to ear and eye. In S. Kornblum (Ed.), Attention and performance $I V$ (p. 101117). New York: Academic.

Tversky, A. (1977). Features of similarity. Psychological Review, 84, 327-352.

Wagner, L., \& Kronlund, A. (2005). False memories of brand names. Bellingham, WA: Northwest Cognition and Memory Conference.

Walsh, G., Hennig-Thurau, T., \& Mitchell, V.-W. (2007). Consumer confusion proneness: scale development, validation, and application. Journal of Marketing Management, 23, 697-721.

Walsh, G., Mitchell, V.-G., Kilian, T., \& Miller, L. (2010). Measuring consumer vulnerability to perceived product-similarity problems and its consequences. Journal of Marketing Management, 26, 146-162.

Zaichowsky, J. L. (2006). The psychology behind trademark infringement and counterfeiting. New Jersey: Laurence Erlbaum. 